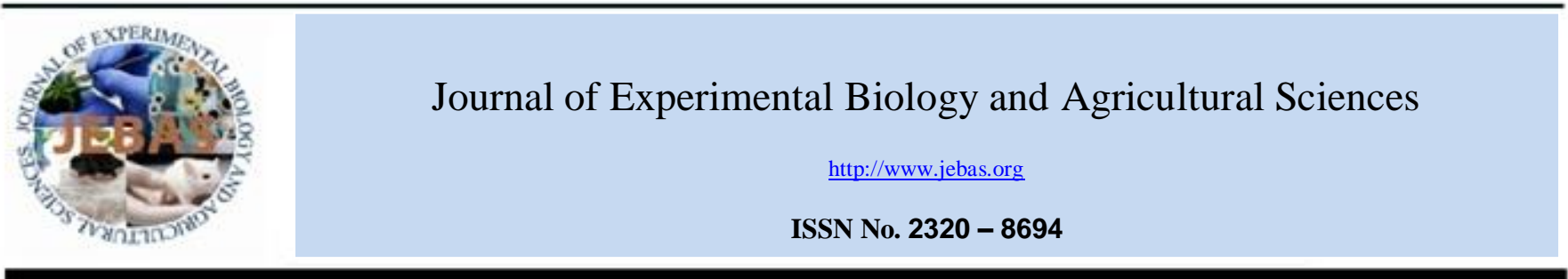

\title{
DESIGN, CONSTRUCTION AND EVALUATION OF GRAIN HARVESTER COMBINE'S HEADER LOSS BASED ON STATISTICAL ANALYSIS AND MODELING THE OPTIMAL FACTORS
}

\author{
Raheleh Fadavi $^{{ }^{*}}$, Shamsollah Abdollahpour ${ }^{1}$, Mohammad Moghaddam $^{2}$
}

${ }^{1}$ Department of Biosystems engineering, Faculty of Agriculture, University of Tabriz, Tabriz, Iran;
${ }^{2}$ Department of Plant Breeding and Biotechnology, Faculty of Agriculture, University of Tabriz, Tabriz, Ira

Received - May 05, 2017; Revision - August 25, 2017; Accepted - September 02, 2017

Available Online - September 10, 2017

DOI: http://dx.doi.org/10.18006/2017.5(4).537.544

\section{KEYWORDS}

Header loss of combine

Designing

Construction

Reel index

Response surface method

\section{ABSTRACT}

This study was conducted to evaluate the efficacy of grain harvester in wheat field, in the West Azarbaijan province of Iran. Efficacy was accessed in both lab and field test, where as lab test included CATIA, V5 R21 design. Data from the sensor and wooden frame were utilized forstatistics analysis. Moreover, the effects of forward speed of combine $(\mathrm{Vc})$ and peripheral speed of reel 's tip (Vr) were also studied on header loss (reel index $=\mathrm{Vr} / \mathrm{Vc}$ ). Statistical analysis study was conducted by the Factorial analysis of variance with randomized complete block design $\mathbf{3}^{\mathbf{2}}$ (4 replications), with the help of SPSS19 software. The result of the Duncan's test found that the differences between means of two trails are significant at 5\% probability level. Paired samples test was used to compare mean between header loss data that have been obtained from wooden frames and two systems, results of study revealed 1.6 and 0.78 reel index (RI). Duncan 's test found that the difference between means of two equipments and wooden frame is not significant. In response surface method, central composite design was used to modeling and finding optimal levels of mentioned factors; at the optimum condition, minimum combine header loss were reported 1.1 for RI.
* Corresponding author

E-mail: fadavi.raheleh@gmail.com (Raheleh Fadavi)

Peer review under responsibility of Journal of Experimental Biology and Agricultural Sciences.

Production and Hosting by Horizon Publisher India [HPI] (http://www.horizonpublisherindia.in/).

All rights reserved.
All the article published by Journal of Experimental Biology and Agricultural Sciences is licensed under a Creative Commons Attribution-NonCommercial 4.0 International License Based on a work at www.jebas.org.

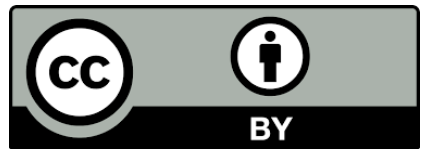




\section{Introduction}

Wheat (Triticum aestivum) has vital and strategical role in human life and consider as the most consumed cereal grains worldwide. The average wheat production during past 36 years was reported 9.25 million ton from Iran and the latest statistics showed that area under wheat cultivated is $51.2 \%$ (Anonymous, 2015). Wheat cultivation mechanisms included a combination of 5 general steps viz. cutting, feeding, threshing, separating and cleaning, among this highest wheat loss was reported during cutting and feeding and in Iran this was higher than the other counties. The reel index, crop density and the cutting height determine the feed rate (which is the amount of crop which can be processed by the machine) and affect all the subsequent processes. Online measuring of header loss by using sensor not been conducted yet in the world. Reel index must be efficient and smooth enough to push the crop into the header and this should be achieved without causing shatter losses from impacting ears and stalks.

Grain loss due to unfavorable land condition is one of the most significant problems encountered during the wheat harvesting in Iran. The major losses of wheat belong to harvesting operation. Rahimi \& Khosrovani (2005) studied the grain losses during harvesting operation in Fars province, and reported that total average loss was $4.81 \%$ and $68 \%$ of this related to header loss. Unfortunately as a result of drought, since past few years header and natural losses have been intensified in Iran. Modern technologies such assensors, communication and computing have generated new revolutionary opportunities in the agricultural sector which resulting in higher crop yield due to better management practice. Till now, worldwide many researches were conducted on yield mapping and loss monitoring in combination. Liang et al. (2016) investigated sensor for monitoring rice grain sieve losses in combine harvesters. Similarly, Zareei \& Abdollahpour (2016) also studied the optimal factors which affecting the harvester header losses in Iran. Further, Yilmaz \& Sagiroglu (2015) developed a measurement system for grain loss of chickpea in Turkey. Similarly, Cho et al. (2014) studied on head-feeding of paddy combine harvesters by using multiple sensors to detect uncut crop edges for autonomous guidance systems in Japan. Considerable research studies have been conducted on modeling combines header losses in different crop harvesting through linear statistical models as function of the parameters such as the moisture content of grain, cutter bar service life, distance between reel fingers, distance of reel fingers from the cutter bar, radius of reel, reel rotational speed per forward speed of combine harvester (reel index), non-dimensional ratio of crop height to the height of reel axis at the top of the ground, stem height and other characteristics of the crops (Oduori et al., 2008; Junsiri \& Chinsuwan, 2009). Response surface method (RSM) is a combination of mathematical and statistical methods and it is useful for the modeling and analyzing a process, it also helps in optimizing the harvesting procedure (Myres \& Montgomery, 1995). The main idea of RSM is to use a sequence of designed experiments to obtain an optimal response. PishgarKomle et al. (2012) used RSM to optimize corn grain harvest losses with corn picker-stipper device and investigated the effect of ground speed and forwarding speed on the loss of corn grain, results of the work showed that the optimal forwarding speed and ground speed to achieve the minimum amount of grain loss were $600 \mathrm{r} / \mathrm{min}$ and $3 \mathrm{~km} / \mathrm{h}$, respectively. Oduori et al. (2008) studied on shattered rice grain loss attributable to the combine harvester reel based on modeling formulation and fitting to field data in Japan. The main objective of this study is to evaluate an online measurement system of header loss; results obtained in this system compared with wooden frame and estimate related defects of the system and represent the optimization model using response surface method. In order to improve the process of harvesting, investigations of notifying loss by machine operation is important object; further, study also estimatedthe loss in real-time by designed equipment in specific area then calculated and related it for one hectare in addition statistical analysis and modeling the optimal factors based on the collected data from farm.

\section{Materials and Methods}

Present study was conducted at the Oromieh Township which is the center of West Azarbaijan province, Iran during the harvesting season of 2015-2016. The West Azarbaijan is located in the northwestern Iran located at $44^{\circ} 3^{\prime}$ to $47^{\circ} 24^{\prime}$ eastern longitude, and $36^{\circ} 5^{\prime}$ to $39^{\circ} 46^{\prime}$ northern latitude. Crop which was cultivated during the study period was wheat variety Pishgam with average yield of about $4 \mathrm{t} / \mathrm{ha}$.Combine used for the test was manufactured by CLASS LEXION 68s. This research included design and selection system, testing, evaluation and statistical analysis (Under laboratory and field test).

\subsection{Design and selection system}

The design of innovative system must be in principle comply with the necessary requirements for its construction and in principle it dependent on its functioning. The main function of the designed system is to collect, transfer and measure the discharging loss from the system to ensure the coverage all of the header loss (Combine header losses of grains are seeds coming out with straw and chaff from the bottom of header or as complete clusters or clusters along with the stem from the front of header). The sketch of the simulation model used at the initial stage of this study was designed by using CATIA (V5R21) software. Zareei et al. (2013) designed first equipment for measuring header loss for 1 line culture in German (Figure 1); construction criteria of this equipment was based on the movement, high safety, lower costs, 
easy to install and high coverage in order to collecting header loss for 1 line culture. This mainly comprise of collecting loss made by two PVC half pipes (tubes diameter 110 and $125 \mathrm{~mm}$ ), $1.5 \mathrm{~m}$ length and collected head loss was separated and measured manually.

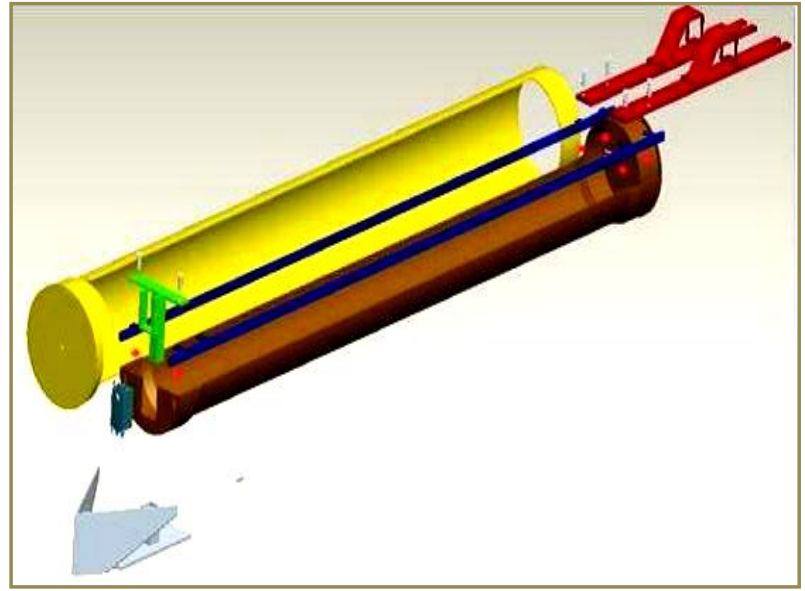

Figure 1 First equipment for measuring of header loss for 1 line culture in German (Zareei et al., 2013)

As already mentioned that aim of the present study was to collect and measure online loss so developed machine included mechanical and electronic segments to achieve objects of this paper. Figure 2 has been shown three dimensional views along with its components of the developed system.

This system should tightly hold the underneath screws of cutter bar and this was achievement by measuring the distance between screws which are located under the cutter bar. Based on the available space on the installation and placement site of this system, other sizes and distances were estimated by utilizing of wooden model in lab. According to the available space and shape of the system, it was not possible to apply alternator as a power source so in this study feasible procedures was used and sun wheel model was used; tines soak of this was started rotate in soil. Furthermore the size and number of tines were determined during field test. Because of the slope of this system as a result of cutting angle in cutter bar, this system has tilt to the ground, subsequently; losses can be discharged on the land after measurement by assistance the force of gravity. Additionally, in order to investigate loss in different regions of cutter bar width and to increase replications in trail two equipments were constructed. Klinner \& Bigger (1972) studied the front losses in combine and reported that the table losses in the region of the dividers were significantly higher. All of the used mechanisms in this study were designed according to cutter bar and reel condition additionally shattering model.

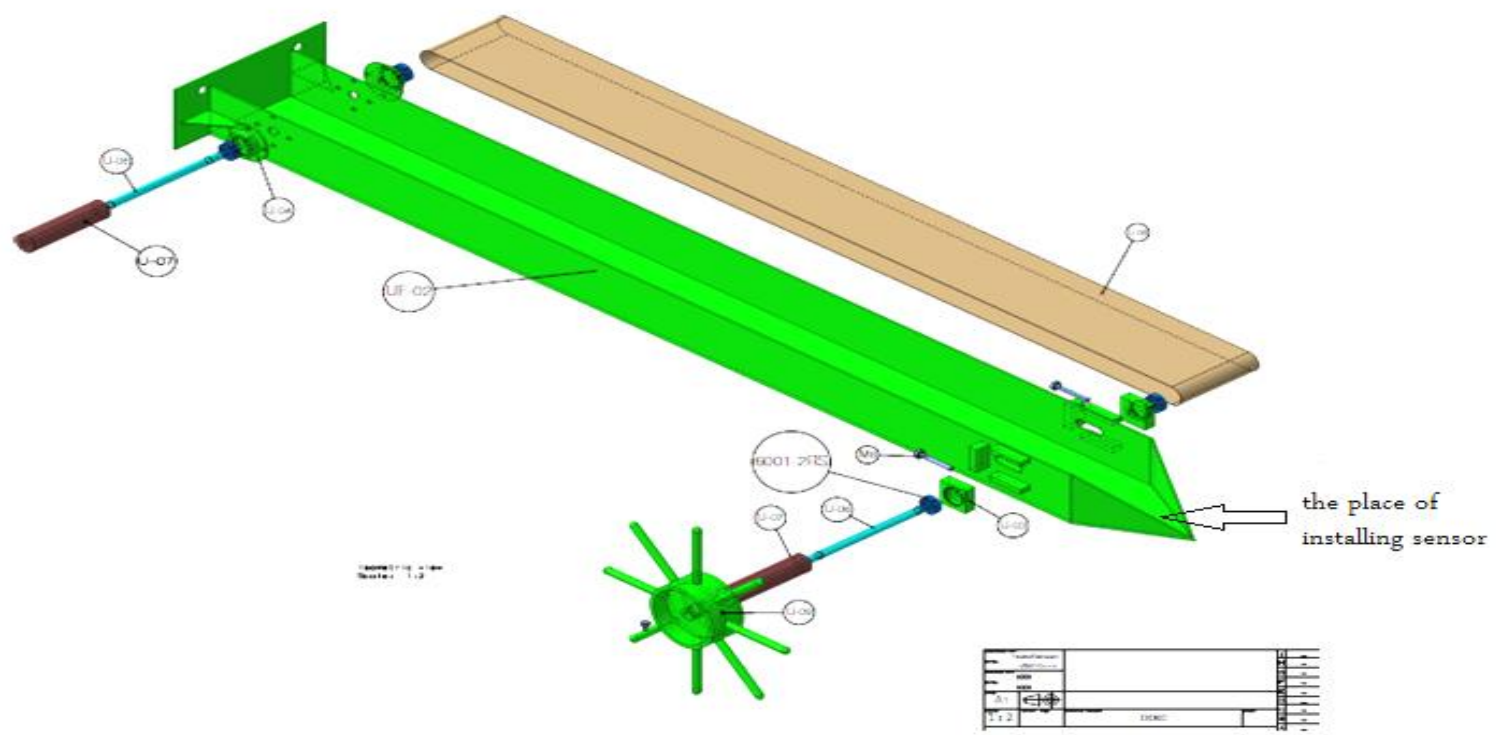

Figure 2 Three dimensional view of developed system alongwith its components (assembling) 


\subsection{Sensors}

Because of high noise, dust and difficult condition in farm, selection of proper sensor was the most important step for any study, in this study a 0-300 gr load cell (based on wheat stone bridge) was designed and used. Further, Proteus (for circuit design and hardware part, Figure 3) and BASCOM-AVR (for programming and software part) was used for the sensor designing. Loadcell was calibrated by 0,50 and 100 weights. Figure 4 has been shows the constructed loadcell. The load cell was installed on the front of the system after collecting data and entering to laptop as a result of high accuracy, outlier data were deleted. After each replication, data loss was entering to laptop.

After construction, the equipment was tested and results of the test carried out were subjected to statistical analysis. Further, to conduct these experiments, the most effective factors on header loss and their appropriate levels were estimatedand this was followed by the loss values measurement in different condition arising from the change of factors levels. Zareei et al. (2013) considered four parameters including reel index, cutting height of crop, horizontal distance of reel from cutter bar and vertical distance of reel from cutter bar, each of them in three levels while In present study, just two factors were studied; designing, construction and evaluation of target system was considered as main point. Statistical experiments were conducted on the basis of the results obtained in Factorial experiments; this study was conducted in randomized complete block design $3^{2}$ replications (Table 1). Multiple regressions were used to express relation between dependent and independent parameters. Independent variables used in this experiment were forward speed of combine $(\mathrm{Vc})$ and peripheral speed of reel 's tip (Vr) (Reel Index $=\mathrm{Vr}$ / $\mathrm{Vc}$ ); loss of head was assumed as dependent variable. $\mathrm{Vr}$ is expressed as Equation (1):

$\mathrm{Vr}=r \omega=\frac{2 \pi r n}{60}$

Whereas, $\mathrm{Vr}$ - peripheral speed of reel 's tip $(\mathrm{m} / \mathrm{s}) ; \mathrm{r}$ radius of reel $(\mathrm{m}) ; \mathrm{w}$ - angular velocity $(\mathrm{rad} / \mathrm{s}) ; \mathrm{n}-\mathrm{rpm}$

Before testing in farm, natural loss was measured by wooden frame according to the instructions of loss measurements, and later on natural loss would be
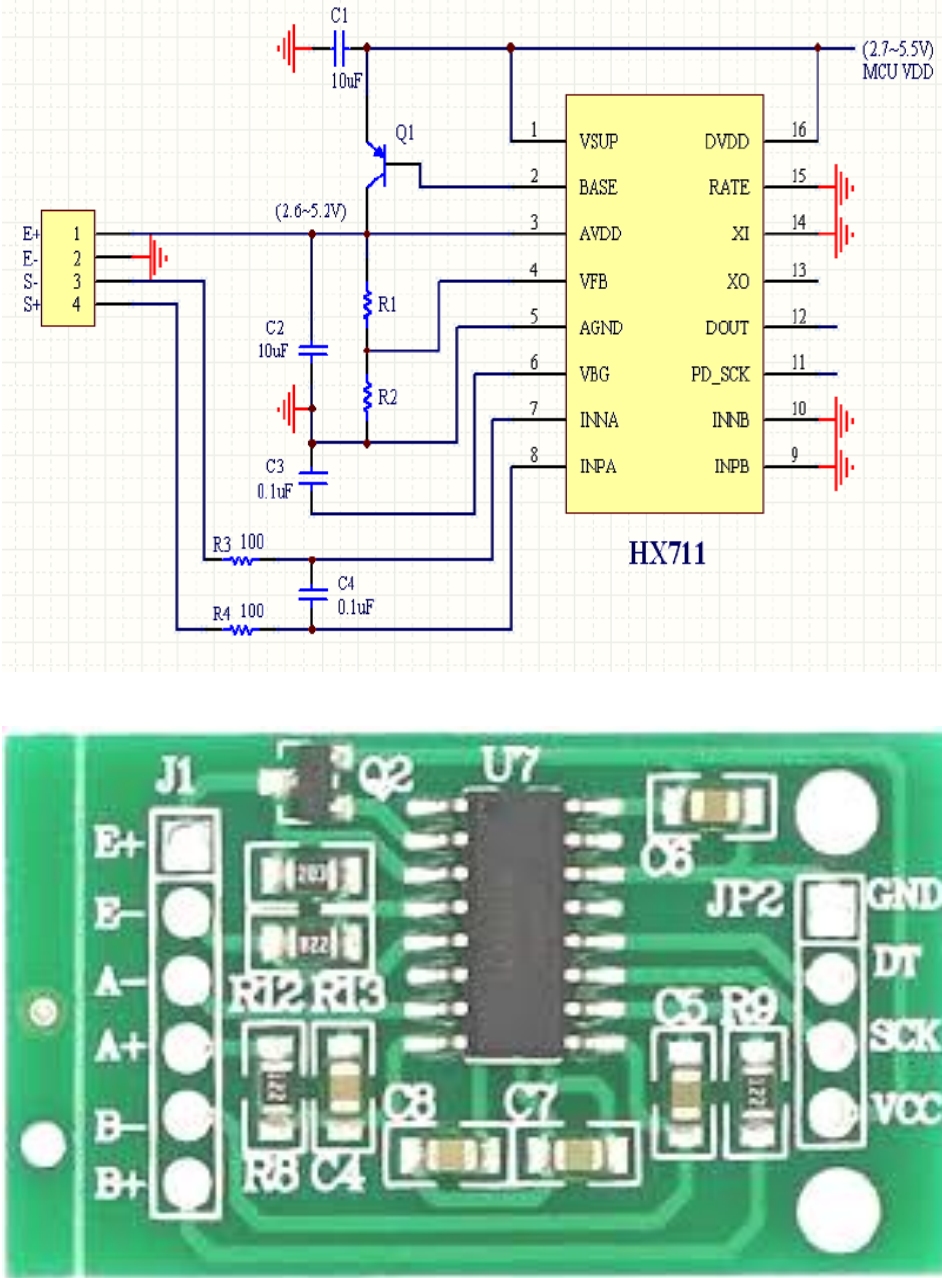

Figure 3 Designed circuit and other hardware part of the developed system

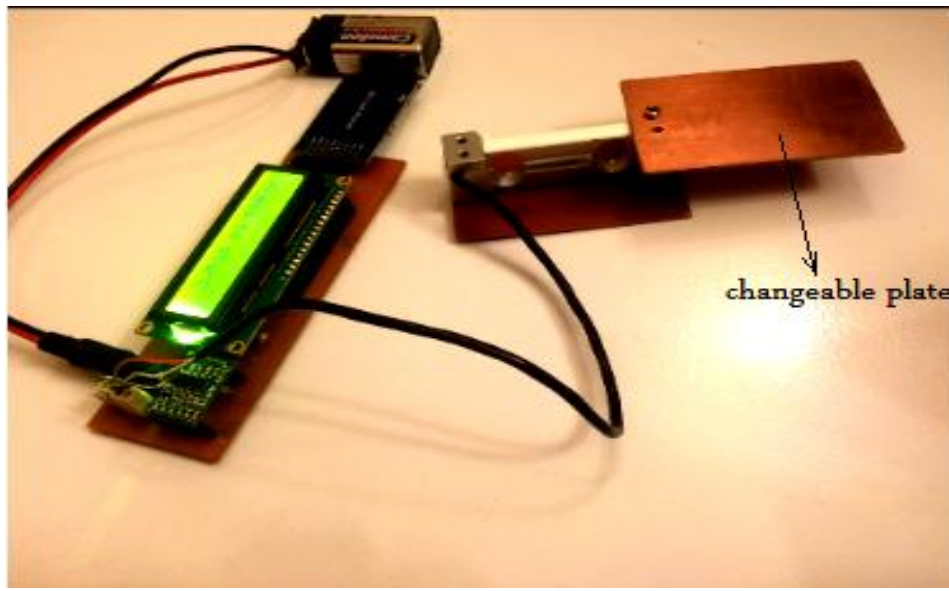

Figure 4 Picture showing constructed loadcell 
subtracted from header loss which was measured by wooden frame. During farm testing, all effective factors had been kept in constant and proper level in order to decline their effects on head loss and following highlighting the effects of studied variables. Mirzazadeh et al. (2011) studied on effect of operation parameters on threshing efficiency control the amount of threshing loss based on ANOVA and Multiple regression.

Table 1 Combine header operation parameters and their corresponding amount

\begin{tabular}{|lccc|} 
& $\begin{array}{c}\mathrm{V}_{\mathrm{r} 1}=1.05 \\
\mathrm{~m} / \mathrm{s}\end{array}$ & $\begin{array}{c}\mathrm{V}_{\mathrm{r} 2}=1.31 \\
\mathrm{~m} / \mathrm{s}\end{array}$ & $\begin{array}{c}\mathrm{V}_{\mathrm{r} 3}=1.57 \\
\mathrm{~m} / \mathrm{s}\end{array}$ \\
\hline $\mathrm{V}_{\mathrm{cl}}=3.5 \mathrm{~km} / \mathrm{h}=0.98 \mathrm{~m} / \mathrm{s}$ & $\mathrm{RI}_{1}=1.07$ & $\mathrm{RI}_{4}=1.34$ & $\mathrm{RI}_{7}=1.6$ \\
\hline $\mathrm{V}_{\mathrm{c} 2}=4.2 \mathrm{~km} / \mathrm{h}=1.176 \mathrm{~m} / \mathrm{s}$ & $\mathrm{RI}_{2}=0.89$ & $\mathrm{RI}_{5}=1.114$ & $\mathrm{RI}_{8}=1.335$ \\
\hline $\mathrm{V}_{\mathrm{c} 3}=4.8 \mathrm{~km} / \mathrm{h}=1.344 \mathrm{~m} / \mathrm{s}$ & $\mathrm{RI}_{3}=0.78$ & $\mathrm{RI}_{6}=0.97$ & $\mathrm{RI}_{9}=1.168$ \\
\hline
\end{tabular}

Before installing and applying the equipments, header loss was estimated. After entering to the farm, combine harvested at a specific rate about $30 \mathrm{~m}$ to reach steady state. Then, wooden frames $\left(50 \times 50 \mathrm{~cm}^{2}\right)$ were placed at some point from harvested parts which only the header passes from over it and materials got out from the back of combines are not poured into it, to measure the combine header loss of grains and clusters in the frames, these two were collected and weighted; same was replicated and measured four times for each treatment.

In addition to this, response surface methodology and software Statistical analysis were used to obtain a response surface based on central composite design. The purpose of response surface method is to find the appropriate amount of combine header loss.

\subsection{Header loss under laboratory and field conditions}

Three main objective of the lab test was (i) selection of the suitable place of installing equipments (Figure 5), design, construction and assembling of the equipment (ii) selection, designing and construction of the sensor (iii) testing of the equipment and performance of sensor. Slippage of conveyor and shattering grain to chassis of the system were solved.

Required tools for conducting field test include wooden frames $(50 \times 50 \mathrm{~cm} 2)$, meter, scissors of horticulture, plastic bags and chronometer for measuring time $[\mathrm{t}(\mathrm{s}) \times$ forward speed of combine $(\mathrm{m} / \mathrm{s})=$ traveled distance by combine $(\mathrm{m})]$, then the systems were joined to combine and field test was conducted in wheat farm (Figure 6). Header losses would be measured in two ways: one by wooden frame and second by two systems, then obtained data would be compared by SPSS19 software, Student 's t-distribution and Duncan test.

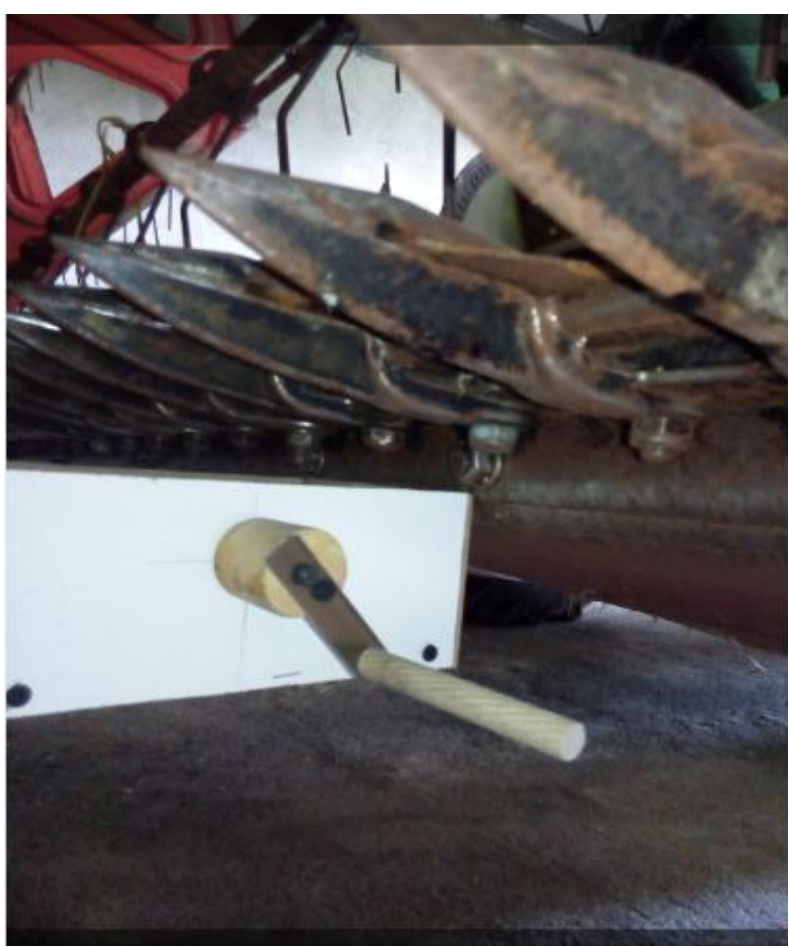

Figure 5 Showing selecting the suitable place of installing equipments

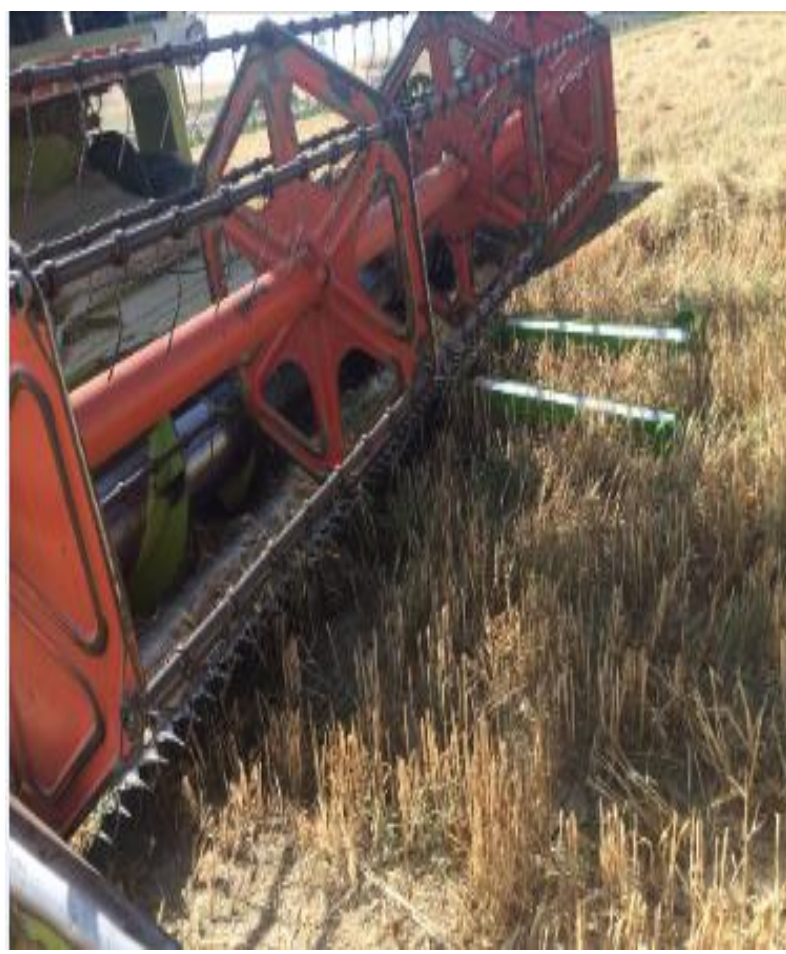

Figure 6 Showing Field test efficacy of the developed system 


\section{Results and Discussion}

3.1 The results of ANOVA and Multiple regressions on accuracy of the system

All data analysis of experimental design was performed by using SPSS19; the results of ANOVA have been presented in Table 2. The effect of two independent variables, $\mathrm{Vc}$ and $\mathrm{Vr}$ was evaluated by Factorial experiments with randomized complete block design $3^{2}$ ( 9 treatments) for header loss testing. Furthermore experiments were conducted in 4 replications. All factors have a possibly significant effect on header loss. Results of study indicated that the header loss is varying in investigated area of head. Further, it was reported that variables and Rep (block) had significant effects on the combine header loss. It was also reported that when all of effective factors related to header loss kept in fix level, consequencely the effects of $\mathrm{Vc}$ and $\mathrm{Vr}$ were more significant. The Interaction of $\mathrm{Vc}, \mathrm{Vr}$ was significant, this means that $\mathrm{Vc}, \mathrm{Vr}$ are adjusted together. Studies showed that the optimum value of RI is 1-1.5 and this ratio depends on the types of the crop and environmental condition.

Relation between the inputs and loss was estimated by using multiple regression and the loss $(\mathrm{g} / \mathrm{ha})$ was assumed to be a

Table 2 Effects of various speed combination of header loss statistical

\begin{tabular}{|llllcc|}
\hline \multicolumn{7}{|c}{ Source } & \multicolumn{1}{c}{$\begin{array}{c}\text { Sum of } \\
\text { squares }\end{array}$} & df & $\begin{array}{c}\text { Mean } \\
\text { square }\end{array}$ & $\mathrm{F}$ & Sig. \\
\hline Model & $438.244(\mathrm{a})$ & 11 & 39.840 & 28.29 & .000 \\
\hline $\mathrm{V}_{\mathrm{c}}{ }^{*} \mathrm{~V}_{\mathrm{r}}$ & 261.161 & 4 & 65.290 & 46.363 & .000 \\
\hline $\mathrm{V}_{\mathrm{c}}$ & 80.737 & 2 & 40.369 & 28.666 & .000 \\
\hline $\mathrm{V}_{\mathrm{r}}$ & 48.264 & 2 & 24.132 & 17.136 & .000 \\
\hline Rep & 48.082 & 3 & 16.027 & 11.381 & .000 \\
\hline Error & 33.798 & 24 & 1.408 & & \\
\hline Total & 80410.180 & 36 & & & \\
\hline $\begin{array}{l}\text { Corrected } \\
\text { Total }\end{array}$ & 472.042 & 35 & & & \\
\hline
\end{tabular}

a R Squared $=.928$ (Adjusted R Squared $=.896$ )

function of $\operatorname{Vr}(\mathrm{m} / \mathrm{s})$ and $\mathrm{Vc}(\mathrm{m} / \mathrm{s})$. The results of multiple regression models in terms of factors are expressed by Equation 2:

$$
y=7.090 \mathrm{Vc}+13.107 \mathrm{Vr}
$$

Abdi \& Jalali (2013) predicted combine harvester header losses based on mathematical model. In present study also three main treatments (ground speed, reel speed and reel height) were considered as three levels in factorial experiment and all three treatments have four replication. Model showed the coefficient of determination $\left(\mathrm{R}^{2}\right)$ equal to 0.6292. Similarly, Junsiri \& Chinsuwan (2009) reported that head grain loss increased with increase in reel rotational speed and reel height. Above mentioned equation 2 indicate that the constant is zero which means loss is not zero unless combine and reel remain in static state. In table 3, coefficient of determination was obtained $\left(r^{2}=0.81\right)$ while the standardized coefficient associated with $\mathrm{Vc}$ was greater than $\mathrm{Vr}$.

Table 3 Various coefficient of determination used in study

\begin{tabular}{|c|c|c|c|c|c|}
\hline Model & \multicolumn{2}{|c|}{$\begin{array}{c}\text { Un-standardized } \\
\text { Coefficients }\end{array}$} & \multicolumn{2}{c|}{$\begin{array}{c}\text { standardized } \\
\text { Coefficients }\end{array}$} & Sig. \\
\cline { 2 - 4 } & B & $\begin{array}{c}\text { Std. } \\
\text { Error }\end{array}$ & \multicolumn{2}{|c|}{ Beta } & \\
\hline Constant & 0 & 0 & 0 & 0 & \\
\hline $\mathrm{V}_{\mathrm{c}}$ & 7.090 & 1.095 & 0.630 & 6.476 & 0.000 \\
\hline $\mathrm{V}_{\mathrm{r}}$ & 13.107 & 3.466 & 0.368 & 3.782 & 0.001 \\
\hline
\end{tabular}

3.2 Results of means between two equipments and two ways of loss measurements

Results of Duncan's test represented in Table 4 revealed that the difference between means of two equipments is significant at $5 \%$ probability level. This means shattering in different regions of cutter bar is varied. Variance within the groups is higher as compare to the between the groups, this is because of the measuring loss by different RIs. Similarly, Klinner \& Bigger (1972) studied the front losses of combine harvesters and found that the table losses in the region of the dividers are significantly higher.

Table 4 Results of Duncan's test

\begin{tabular}{|lllllll|} 
& $\begin{array}{c}\text { Sum of } \\
\text { Squares }\end{array}$ & df & $\begin{array}{c}\text { Mean } \\
\text { Square }\end{array}$ & F & Sig \\
\hline Between Groups & 51.600 & 1 & 51.600 & 4.316 & $0.045^{*}$ \\
\hline Within Groups & 406.496 & 34 & 11.956 & & \\
\hline Total & 458.096 & 35 & & & \\
\hline
\end{tabular}

*: significant at $5 \%$ probability level

In Table 5 and 6 , header loss data which have been obtained from wooden frames and two systems were analyzed by t test and Duncan. Results presented table 5 suggested that continuous shattering of material during harvesting lead to the reduction in 
Table 5 Paired samples Test for evaluating the harvesting loss on wooden frames and two systems

\begin{tabular}{|c|c|c|c|c|c|c|}
\hline \multirow[t]{2}{*}{ Treatment } & \multicolumn{3}{|c|}{ Paired Differences } & \multirow[t]{2}{*}{$\mathrm{t}$} & \multirow[t]{2}{*}{ df } & \multirow[t]{2}{*}{ Sig. (2 tailed) } \\
\hline & Mean & Std. Deviation & Std. Error Mean & & & \\
\hline $\mathrm{RI}_{5}=1.114$ & -1.02500 & 2.80877 & 1.40438 & -0.730 & 3 & 0.518 \\
\hline $\mathrm{RI}_{1}=1.07$ & -0.50000 & 1.05515 & 0.52757 & -0.948 & 3 & 0.413 \\
\hline $\mathrm{RI}_{9}=1.168$ & -0.67500 & 0.79739 & 0.39870 & -1.693 & 3 & 0.189 \\
\hline $\mathrm{RI}_{8}=0.97$ & -0.42500 & 0.33040 & 0.16520 & -2.573 & 3 & 0.082 \\
\hline $\mathrm{RI}_{6}=1.335$ & 2.50000 & 1.61452 & 0.80726 & 3.097 & 3 & 0.053 \\
\hline $\mathrm{RI}_{2}=1.34$ & 2.22500 & 1.30480 & 0.65240 & 3.410 & 3 & 0.042 \\
\hline $\mathrm{RI}_{4}=0.89$ & 5.22500 & 2.93300 & 1.46650 & 3.563 & 3 & 0.038 \\
\hline $\mathrm{RI}_{3}=1.6$ & 3.65000 & 1.20692 & 0.60346 & 6.048 & 3 & 0.009 \\
\hline $\mathrm{RI}_{7}=0.78$ & 8.80000 & 2.54558 & 1.27279 & 6.914 & 3 & 0.006 \\
\hline
\end{tabular}

Table 6 Results of Duncan test based in the factorial data obtained from the study

\begin{tabular}{|l|ccc|}
\hline & Sum of squares & df & Mean Square \\
\hline Between Groups & 92.480 & 1 & 92.480 \\
\hline Within Groups & 1641.818 & 70 & 23.455 \\
\hline Total & 1734.298 & 71 & \\
\hline
\end{tabular}

the accuracy of system. In RI 1.6 and 0.78 , difference between wooden frames and two systems were more significant. Duncan's test found that the difference between means of two equipments and wooden frame is not significant; as a result of high level of loss, this system is not able to measure loss correctly and the accuracy of a system decreases.

\section{Results of RSM analysis}

In Figure 7 independent variables interactions ( $\mathrm{Vc}$ and $\mathrm{Vr}$ ) on the combine header loss have been illustrated by using threedimensional diagram of response surface. Figure 7, had a quadratic curve which shows the relationship between $\mathrm{Vc}$ and header loss, this quadratic curve has minimum value at level one $(3.6 \mathrm{~km} / \mathrm{h})$ and by increasing $\mathrm{Vc}$, header loss also increases. Similarly, relationship between $\mathrm{Vr}$ and header loss also have quadratic curve which has the minimum amount at level one (1.1 $\mathrm{m} / \mathrm{s}$ ) and by increasing $\mathrm{Vr}$, header loss also increases. These analyzed results suggest the simple effects of $\mathrm{Vc}$ and $\mathrm{Vr}$ on header loss individually. Further, this study emphasized in the ratio of $\mathrm{Vc}$ , $\mathrm{Vr}$ (RI) and suggest the optimum estimated ratio is 1.1. As a result of low reel rotational speed and high $\mathrm{Vc}$, the fingers are not able to collect and direct them to the head, hence shattering increases. In addition, by increasing reel rotational speed and decreasing $\mathrm{Vc}$, header loss increases too much because of the strong hit of fingers to clusters.

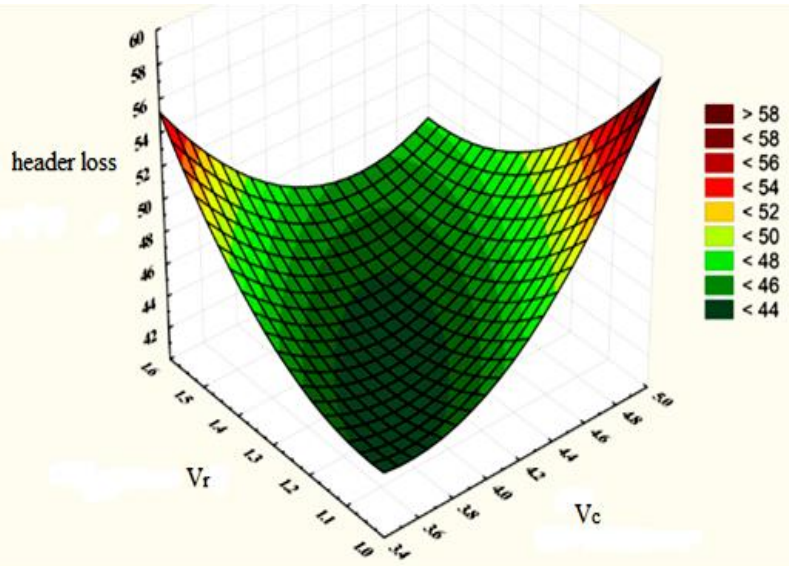

Figure 7 Effect of Vc and Vr on combine header loss

\section{Conclusion}

This research is assumed as initial investigation in this field and the results of this study suggest that measurement of online header loss during harvesting is possible. This study especially emphasized on practice and technical knowledge. In future research, practice used in this study can be improved by using new technologies like machine vision with more factors involved, 
image processing, then setting of combine during harvesting to reduce header loss, etc. Use of this technology for other crops is also proposed, consequently, expense and energy will not be wasted in agriculture.

\section{References}

Abdi R, Jalali A (2013) mathematical model for prediction combine harvester header losses. International Journal of Agriculture and Crop Sciences 5: 549-552.

Anonymous (2015) Investigation of Statistics harvested area and production crops in during 36 years: 1978-2013. 2015. Tehran, Ministry of Agriculture, Department of Planning and Economic, Center of Information and Communication Technology.

ChoW, Iida M, Suguri M, Masuda R, Kurita H (2014) Using multiple sensor to detect uncut crop edges for autonomous guidance systems of head-feeding combine harvesters. Engineering in Agriculture, Environment and Food 7: 115-121.

Junsiri C, Chinsuwan W (2009) Prediction equation for header losses of combine harvesters when harvesting Thai Hom Mali rice. Songklanakarin Journal of Science and Technology 31: 613-620.

Klinner WE, Bigger GW (1972) Some effect of harvest date and design features of the cutting table on the front losses of combine-harvesters. Journal of Agricultural Engineering Research17 : 71-78.

Liang Z, Li Y, Xu L, Zhao Z (2016) Sensor for monitoring rice grain sieve losses in combine harvesters. Biosystem Engineering 147: 51-66.
Mirzazadeh A, Abdollahpour SH, Moghaddam M (2011)Effect of Design Parameters on Separation of Grain in Thresher to Minimize Separation Loss of Combine. Journal of Agriculture Knowledge and Stable Production, 21/2(1): 57-67. (in Persian)

Myres RH, Montgomery DC (1995) Response surface methodology: Process and product optimization using designed experiments, New York: John Wiley \& Sons, Inc.

Oduori MF, Mbuya TO, Sakai J, Inoue E (2008) Attributable to the Combine Harvester Reel: Model Formulation and Fitting to Field Data. Agricultural Engineering International: the CIGR Ejournal, Vol X.

Pishgar- Komleh S, Keyhani A, Mostofi- Sarkari MR, Jafari A (2012) Application of response surface methodology for optimization of picker-husker harvesting losses in corn seed. Iranica Journal of Energy and Environment 3: 134-142.

Rahimi H, Khosrovani A (2005) Determination of wheat losses in harvesting process and investigating same factors affecting it in Fars province. Pajouhesh and Sazandegi, 67: 50-59. (In Persian)

Yilmaz D, Sagiroglu HC (2015) Development of measurement system for grain loss of some chickpea varieties. Measurement 66: 73-79.

Zareei S, Abdollahpour SH (2016) modeling the optimal factors affecting combine harvester header losses. Agricultural Engineering International Journal $18: 60-65$.

Zareei S, Abdollahpour SH, Moghaddam M (2013) Decision making and designing of Fuzzy Control System based on mathematical model of grain combine header loss. $\mathrm{PhD}$ Thesis submitted to the University of Tabriz, Iran (In Persian). 